\title{
Effects of a thinning regime on stand growth in plantation forests using an architectural stand growth model
}

\author{
Y. Chiba \\ Forestry and Forest Products Research Institute, Japan
}

\begin{abstract}
The architectural form of a tree results from a combination of its physiology and mechanical support requirements. Using mathematical models of tree architecture that describe the mechanical relationships between different tree organs, a forest growth model was developed to predict the effect of thinning operations on tree/stand growth. The model is based on the height growth of trees, which is strongly correlated with forest site condition. The crown form of a tree alters as a result of available growing space within the stand, which, thus, affects crown depth. The parameter crown depth is a key characteristic for quantifying individual tree growth in order to reflect the effect of the thinning regime in plantation forests. The applicability of the model was verified using real stand growth data under various thinning regimes. Since the model includes not only the crown form but also the stem form of individual trees, we can predict tree size (clear bole length, stem diameter, ring width), stem shape, tree weight and stand biomass over the course of stand development for a variety of thinning operations. Without any thinning, the forest canopy will close at an early growth stage, there will be a high stand density, and the crown depth will be restricted and will exhibit poor growth. In contrast, forest plantations that are exposed to a number of thinning operations, at an appropriate intensity and timing, will exhibit the required biomass growth and wood quality. The effects on $\mathrm{CO}_{2}$ fixation were also discussed with reference to thinning regimes in plantation forests.
\end{abstract}

Keywords: biomass increment, NPP, stand density control, biomass allocation, tree architecture. 


\section{Introduction}

It is assumed that forested areas contribute to the fixation of atmospheric carbon dioxide, which would otherwise promote global warming [3,9]. Much effort has been exerted in the monitoring of $\mathrm{CO}_{2}$ budgets, including eddy covariance measurements in a variety of forested areas across the world, and quantifying the potential $\mathrm{CO}_{2}$ sequestration of various forest functional types and climatic conditions [2]. Forests in a natural environment are likely to be affected by a variety of factors such as climatic conditions, stand density, transitional stages and soil conditions. We, therefore, need mechanistic and process-based simulation models [2,6] in order to evaluate $\mathrm{CO}_{2}$ fixation by forests and the effects of both global environmental change and human activities, including forest management.

The $\mathrm{CO}_{2}$ budget of forest ecosystems remains unclear even in man-made forests where tree size distribution, forest structure, and environmental gradients in the canopy appear to be considerably simplified. In this paper, a stand growth model is presented; it simulates the growth processes of forest trees in even-aged plantation forests with different thinning treatments. This model is based on the architectural development of trees with changing crown structure over the course of thinning. Architectural models of tree form [3-5] have been formulated to describe quantitative patterns of branching structure and stem formation. The objectives of this study were to quantify the architectural development of forest structure as affected by the forest management associated with various thinning regimes.

\section{Data used}

In order to understand and compare the effect of thinning treatments on timber production in plantation forests, many reports relating to forest biomass were investigated particularly those about sugi (Cryptomeria japonica D. DON) plantations in Japan $[1,8]$. Of the reports linking productivity with stand density, Ando et al. [1] explored the relationship between biomass yields and tree density in several thinned sugi plantations in some traditional forest regions (Yoshino, Nishikawa, Obi, National Forests in Fukushima prefecture). They provide data sets comprising tree sizes (tree height, diameter at breast height, clear length below crown, dry weights of each organ) and tree densities before and after thinning operations. These data were used to characterize general thinning regimes for sugi plantations in order to validate the model presented herein.

\section{Model description}

\subsection{Crown form}

Since tree density (number of stems per hectare) determines the average growing space per tree, the average crown diameter in a stand can be determined using 
this figure. Crown shape is specific to each conifer species [7]. Denoting crown width and crown depth for isolated trees as $C W$ and $C D$, respectively, the following reciprocal equation was defined for conifers:

$$
\frac{1}{C W}=\frac{A}{C D}+\frac{1}{C_{\max }}
$$

where $A$ is a constant that represents the angle at the apex of a tree crown, and $C_{\max }$ is the maximum crown diameter. The constant $C_{\max }$ is dependent on the distance between adjacent trees in the stand, i.e. stand density.

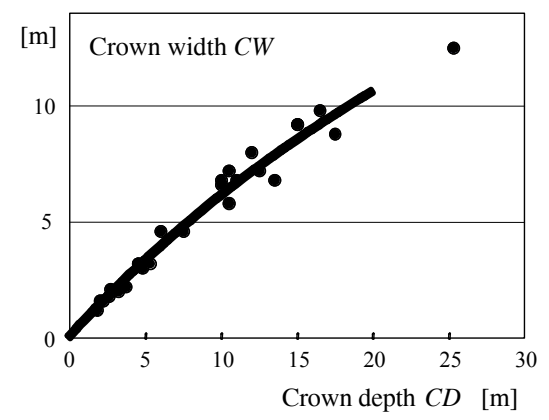

Figure 1: Relationship between crown width and crown depth for conifer crowns.

\subsection{Tree height growth}

It has been reported that tree height is strongly influenced by forest site conditions, including nutritional and water status of the soil. Many researchers have also pointed out that stand density exerts little effect on height growth [8] in plantation forests. In this paper, height growth in sugi plantation forests was approximated by the following formula, which was determined from the data measured in the different stands, irrespective of stand density:

$$
H=H_{\max }\left(1-\exp \left(-a_{\mathrm{H}} / H_{\max } x_{\mathrm{A}}\right)\right)
$$

where $H_{\max }$ denotes the maximum tree height [m] specific to the site, $x_{\mathrm{A}}$ is stand age $[\mathrm{yr}]$ and $a_{\mathrm{H}}$ is the initial height growth $\left[\mathrm{m} \mathrm{yr}^{-1}\right]$ specific to the site.

\subsection{Stem form}

Stem form can be approximated by a hyperbolic function with the two asymptotes of the exponential function representing the upper and lower parts of the stem, respectively [5]. Denoting $z$ as the distance from the apex of a stem, the S-curve [5] is given by 


$$
\frac{1}{S(z)}=\frac{1}{S_{0} \exp (z / \alpha)}+\frac{1}{S\left(z_{\mathrm{B}}\right) \exp \left(\left(z-z_{\mathrm{B}}\right) / \beta\right)}
$$

where $S(z)$ is the stem density (stem weight per unit length) at position $z$ [ $\left.\mathrm{g} \mathrm{m}^{-1}\right]$; $S_{0}$ is the top stem density $\left[\mathrm{g} \mathrm{m}^{-1}\right] ; z_{\mathrm{B}}$ is the distance from the apex to the crown base $[\mathrm{m}] ; \alpha$ is a constant specific to each individual tree, termed the "top taper length" $[\mathrm{m}]$; and $\beta$ is a constant specific to each individual tree, termed the "specific stress length" [m]. By definition, $z_{\mathrm{B}}$ corresponds to the crown depth.

Of the constants in eqn (3), $S_{0}$ and $\alpha$ can be regarded as being independent of tree size, and $S\left(z_{\mathrm{B}}\right)$ and $\beta$ can be approximated by an allometric function based on crown length $\left(=z_{\mathrm{B}}\right)$. Therefore, stem form eqn (3) can be represented by the values of crown length of each tree. In addition, each crown length is likely to be determined mainly by available growing space for the tree, so that average crown length is a function of stand density.

\subsection{Tree weight}

Since leaves and branches of an individual tree are restricted to the tree crown, some attributes of the crown could be employed to estimate the weights of leaves and branches of each individual tree. In this paper, the following allometric relationships between the weights of leaves and branches and crown depth were adopted:

$$
w=a C D^{b}
$$

where $a$ and $b$ are constants, $C D$ is the crown depth and $w$ is the weight of an organ (branches or leaves). Stem weight of each tree was approximated as follows:

$$
w_{\mathrm{S}}=g\left(D^{2} H\right)^{h}
$$

where $w_{\mathrm{S}}$ is stem weight, $D$ is stem diameter at breast height, $H$ is tree height and $g$ and $h$ are constants.

\subsection{Thinning effects on a tree crown}

Just after tree planting, the canopy is unlikely to be closed and the tree crowns will not be overlapped so the height of the lowest branch could be zero. Once the canopy closes, lower branches gradually wither and are shed, and the height at the crown base will increase as the tree increases in height (fig.2). Provided that the stand density remains constant after canopy closure, the crown depth may remain almost constant. However, once the canopy is opened up by thinning, the height at the crown base may remain unchanged until the canopy closes again.

After the canopy closes again, the height at crown base may increase along with the tree height. In other words, crown depth will increase stepwise with every thinning operation. Thus, the process of crown development could be 
linked to thinning treatments. In the present study, crown depths before and after thinning were calculated as follows. An average crown width $C W$ was determined on the basis of stand density. From eqn (1), crown depth $C D$ was determined from the $C W$ for closed canopy. After thinning, the comparison between the current crown depths and the potential crown depth for the current stand density was used to determine whether the canopy had already closed.

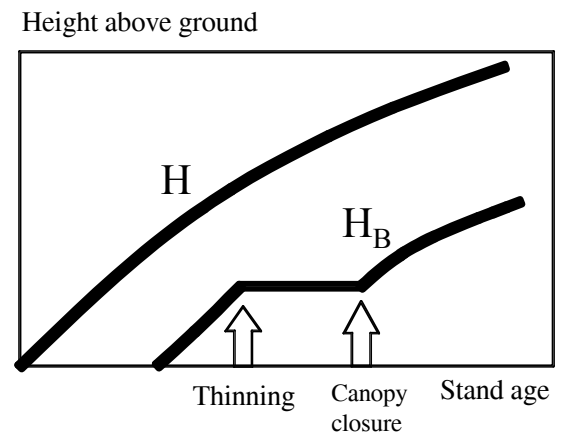

Figure 2: $\quad$ Schematic illustration of tree heights $H$ and height at crown base $H_{\mathrm{B}}$ against stand age.

\section{Results and discussion}

\subsection{Typical thinning regime in sugi plantations in Japan}

For the purpose of timber production for general use, between 2,500 and 4,000 sugi cuttings or seedlings are planted per hectare. The plantations are thinned three or four times, reducing the stocking to a final level of about 700 stems per hectare. Thinning operations are usually completed by ca. 40 years of age. The trees are harvested at about 60 years. This pattern of tending work is widely used in Japan. In contrast, some private foresters undertake specific labor-intensive and carefully planned forestry in order to produce timber for specific uses such as alcove posts or "sake" barrels. They establish dense plantations with over 10,000 trees per hectare, and conduct frequent thinning operations to produce timber from appropriately sized trees, until the final harvest when the trees are around 100 years old. The chronology of this silvicultural system is summarized in table 1 .

\subsection{Tree size development}

The results of the simulation are shown in fig. 3, as applied to typical thinning regimes for sugi plantation forests (table 1). Height at the crown base $H_{\mathrm{B}}$ and diameter at breast height $D$ were based on actual tree height growth for the sites considered. At the initial planting stage, $H_{\mathrm{B}}$ was almost zero because the canopy had not yet closed. Although the stand age when canopy closure first occurs is 
dependent on stand density, $H_{\mathrm{B}}$ appears to start increasing at a stand age of about 10 years. After this, the crown length $\left(=H-H_{\mathrm{B}}\right)$ shows a gradual increase due to repeated thinning treatments in the course of stand development. Figure 3 demonstrates the close correspondence between the simulation and the real data. Furthermore, stem diameter at breast height, $D$, is also closely approximated by the present model, which uses stem form as presented in eqn (3).

Table 1: Typical thinning regimes for sugi plantations in the National Forest and Yoshino.

\begin{tabular}{ccc}
\hline $\begin{array}{c}\text { Stand age } \\
\text { (year) }\end{array}$ & $\begin{array}{c}\text { National Forest } \\
\text { (stems/ha) }\end{array}$ & $\begin{array}{c}\text { Yoshino } \\
\text { (stems/ha) }\end{array}$ \\
\hline 0 & 3,000 & 14,000 \\
20 & 1,700 & 3,500 \\
30 & 1,200 & 2,000 \\
40 & 850 & 1,500 \\
50 & 750 & 1,000 \\
60 & 590 & 900 \\
\hline
\end{tabular}

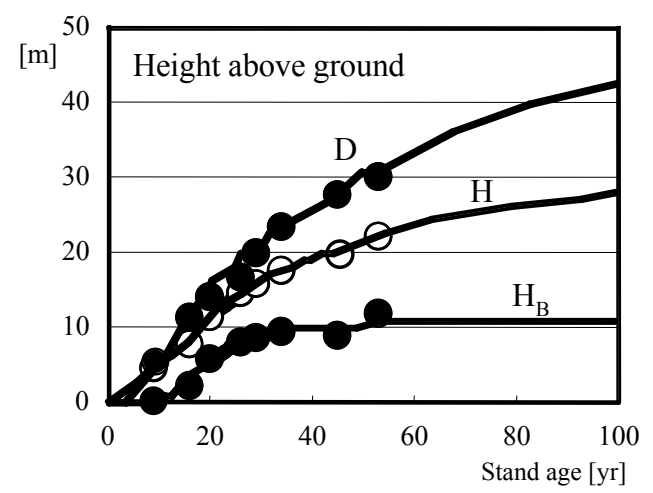

Figure 3: Simulation of tree sizes in a plantation forest with thinning. D, H, and $\mathrm{H}_{\mathrm{B}}$ denote diameter at breast height, tree height and height at crown base, respectively.

\subsection{Biomass growth}

As mentioned above, the mean crown depth, $C D$, of an average tree in a stand can be calculated with a considerable level of accuracy for each stand age. Using these $C D \mathrm{~s}$, the weights of leaves and branches were calculated using eqn (4), and the stem weight was obtained from eqn (5). Finally, we simulated biomass development of sugi plantation forests as shown in fig.4. The saw-tooth appearance of the growth pattern for each organ is the result of the thinning treatments. 


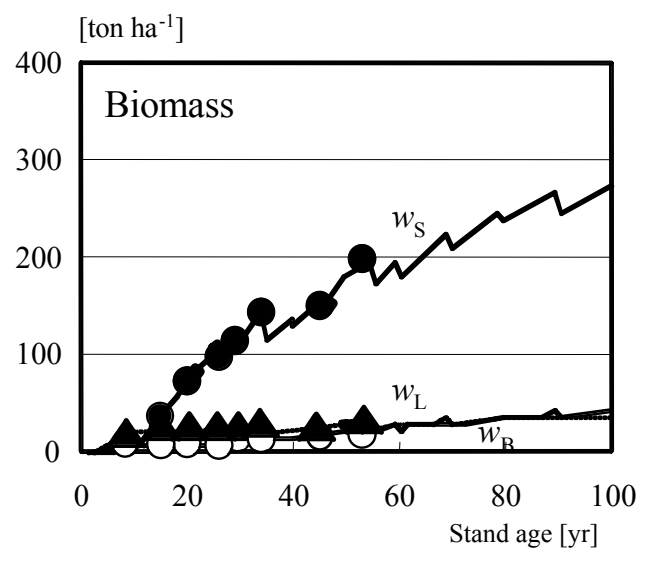

Figure 4: Simulation of biomass growth in a plantation forest with typical thinning regimes. Solid and dashed lines: results of the simulation; symbols: actual data of the biomass of stem $w_{\mathrm{S}}$, branch $w_{\mathrm{B}}$ and foliage $w_{\mathrm{L}}$, respectively.

It is likely that foliage and branch mass reach their maximum levels before the stand is mature. In particular, foliage mass tends to reach its highest level just after canopy closure in the model, this corresponds to the real data from the various sugi stands investigated to date. In contrast, stem mass exhibits continuous incremental growth throughout the life of the stand. Recent reports on biomass of old growth plantation forests demonstrate similar results, with higher stem growth than previously expected, indicating that even in stands over 70-80 years of age, the stem volume of the stand does not decline.

Using the simulation model presented here, $\mathrm{CO}_{2}$ or carbon fixation in forest plantations was evaluated. Much higher $\mathrm{CO}_{2}$ fixation was observed in the early stage of development of dense stands compared to other tending regimes. However, such dense stands are considered at high risk of abiotic disturbances, such as wind throw and snow damage, because of the very slender stems. In addition, it has been demonstrated that $\mathrm{CO}_{2}$ fixation by these dense stands declines rapidly after canopy closure. In contrast, very low density plantations cannot always increase $\mathrm{CO}_{2}$ fixation because they do not fully occupy the available space. Taking these results into account, it is possible that plantation forests managed in the most typical way, like the National Forests, maximize the sequestration of $\mathrm{CO}_{2}$, providing effective and stable conditions.

\section{References}

[1] Ando, T., Hatiya, K., Doi, K., Kataoka, H., Kato, Y. \& Sakaguchi, K., Studies on the system of density control of sugi (Cryptomeria japonica) stand. Bulletin of Government Forest Experiment Station, 209, pp. 176,1968 . 
[2] Baldocchi, D.D., Wilson, K.B. \& Gu, L., How the environment, canopy structure and canopy physiological functioning influence carbon, water and energy fluxes of a temperate broad-leaved deciduous forest-an assessment with the biophysical model CANOAK. Tree Physiol, 22, pp. 1065-1077, 2002.

[3] Chiba, Y., Plant form analysis based on the pipe model theory. I. A statical model within the crown. Ecological Research, 5, pp. 207-220, 1990.

[4] Chiba, Y. \& Shinozaki, K., A simple mathematical model of growth pattern in tree stems. Annals of Botany, 73, pp. 91-98, 1994.

[5] Chiba, Y., A quantitative analysis of stem form and crown structure: the Scurve and its application. Tree Physiol, 7, pp. 169-182, 1990.

[6] Farquhar G.D. \& von Ceamerrer, S., Modeling of photosynthetic response to environment. Encyclopedia of plant physiology, New Series, 12B: Physiological Plant Ecology II, ed. O.L. Lange, P.S. Nobel, C.B. Osmond \& H. Ziegler, Springer-Verlag: Berlin, pp. 549-587, 1982.

[7] Kobayashi, S., Studies on the simulation model of stand growth of Japanese larch (Larix leptolepis GORD.) plantation. Bulletin of the Hokkaido Forest Experiment Station, 15, pp. 1-164, 1978.

[8] Tadaki, Y., \& Hatiya, K., Forest ecosystem and its dry matter production. (Forestry Research Exposition Series 26). Ringyo Kagaku Gijutsu Shinkosho: Tokyo, pp.1-64, 1968.

[9] Thornley, J.H.M. \& Cannell, M.G.R., Modeling the components of plant respiration: representation and realism. Annals of Botany, 85, pp. 55-67, 2000 . 